\title{
IMPACTS OF COVID-19 ON TRAVEL BEHAVIOR OF THE PEOPLE IN BANGLADESH
}

\author{
Farzana AFROZ \\ University of Dhaka, Department of Statistics, Bangladesh, e-mail: farzana_bd87@yahoo.com \\ Kamrul HASSAN* \\ University of Dhaka, Department of Tourism and Hospitality Management, Bangladesh, e-mail: hassan_bd26@yahoo.com \\ Jannatul FERDAUS \\ University of Dhaka, Department of Tourism and Hospitality Management, Bangladesh, e-mail: jannatulria99@gmail.com
}

\begin{abstract}
Citation: Afroz, F., Hassan, K., \& Ferdaus, J. (2022). IMPACTS OF COVID-19 ON TRAVEL BEHAVIOR OF THE PEOPLE IN BANGLADESH. GeoJournal of Tourism and Geosites, 40(1), 56-63. https://doi.org/10.30892/gtg.40106-802
\end{abstract}

\begin{abstract}
In order to formulate necessary strategies related to traveling, it is indispensable to examine travel behavior under COVID scenario. This study aims at assessing travel behavior in terms of different purposes of visit of the travelers of Bangladesh in relation to COVID-19 pandemic. It has utilized quantitative research approach and the data collected were subject to Poisson regression statistical analysis. The results revealed that domestic travel is an important determinant of international travel. In addition to domestic travelers are expected to travel less for leisure, VFR, medical or other purposes compared to the business purpose during COVID period.
\end{abstract}

Keywords: COVID-19, travel behavior, purpose of visit, poisson regression, Bangladesh

$* \quad * \quad * \quad * \quad * \quad *$

\section{INTRODUCTION}

Almost every sector of the world economy has been affected by the COVID-19 pandemic. Among them travel and tourism sector is the most sufferer (European Commission, 2020; Fotiadis et al., 2021; Zhang et al., 2021). Outbreak of this global pandemic has forced several countries to impose travel restrictions, border shutdowns, limitations on internal movement and so on (Karabulut et al., 2020; Qiu et al., 2020). This results in devastating impact on tourism industry. According to WTTC (2021), in 2019, travel \& tourism was among the key sectors of world economy which contributed around USD 9.2 trillion to global GDP, but due to the pandemic its contribution to global GDP declined by $49.1 \%$ and reached to only USD 4.7 trillion in 2020. The tourism industry has seen a number of crises in past few years such as the Severe Acute Respiratory Syndrome (SARS) epidemic in 2003, global economic recession in 2008, and the outbreak of Middle East Respiratory Syndrome (MERS) in 2015. However COVID-19 pandemic is much different from those previous crises in terms of its long duration and severity of the impacts (Gössling et al., 2021; Hassan and Ferdaus, 2020). This is considered as world's deadliest epidemic as it brings some other crisis (e.g. health crisis and financial crisis) along with it (Fotiadis et al., 2021).

The global pandemic COVID-19 has affected the basis of tourism industry by restricting the sociability and mobility of individuals (Qiu et al., 2020). As tourists are very sensitive to crisis so any crisis like COVID-19 extremely affects travel behaviors of tourists. For instance, according to WTTC (2021) in 2020, domestic visitor spending was reduced by $45 \%$ and international visitor spending was decreased by $69.4 \%$. Along with the demand side, due to the restrictions imposed on tourism industry to minimize the transmission of COVID-19, tourism supply-side is drastically damaged too (Bakar and Rosbi, 2020; Kumar, 2020). This industry has suffered a massive loss of almost USD 4.5 trillion in 2020 (WTTC, 2021). The ongoing global pandemic COVID-19 has immense possibility to reform future travel landscapes which is already evident (Gössling et al., 2021). Tourists have an increased appeal for domestic trips (UNCTAD, 2021; Hussain and FustéForné, 2021). Moreover, safety and security has become one of the most significant considerations for tourists in terms of making travel decision and destination selection (Chebli and Ben Said, 2020; European Commission, 2020).

Throughout the course of history, it is reflected that the world has experienced a number of health related crisis ranging from epidemics (e.g. Cholera, flu) to pandemics (e.g. AIDS, plague) (Hall et al., 2020). Over the last decade several diseases outbreak such as Cholera, Ebola, Zika, Swine Flu, and Dengue has had a tremendous impact on travel and tourism sector (Matiza, 2020). According to UNWTO (2021b), during the SARS epidemic in 2003 international tourist arrival was declined by $0.4 \%$ that results in a loss of US\$ 3 million in international tourism receipts. Moreover, in a study Hall et al. (2020) have delineated about the devastating effects of MERS outbreak. In addition the authors have also mentioned that in Korea this epidemic has caused a loss of US\$2.6 billion for tourism industry. At present COVID-19 is wreaking havoc around the world. However these three corona viruses namely SARS-Cov, MERS-Cov, and COVID-19 are highly infectious diseases and cause severe respiratory problems (WHO, 2021). Transmission of such zoonotic diseases has become faster than ever with the pace of globalization (Hall et al., 2020). Thus the disastrous impact of these disease outbreaks has not been limited to only a

\footnotetext{
* Corresponding author
} 
specific country rather ranging over the world (Chebli and Ben Said, 2020). The outbreak of COVID-19 pandemic is considered as the most disastrous crisis the world has ever seen (Gössling et al., 2021; Hall et al., 2020). When the disease was first detected in China back on November 2019, the world has never imagined that the virus would spread so fast and will become a great threat for so many people. Soon after the declaration made by WHO (World Health Organization) about it as a pandemic situation, different countries started taking drastic measures (e.g. locking down the entire country or a specific area, imposing restrictions on travel, closing schools and other institutions) to limit the transmission (Fotiadis et al., 2021; Qiu et al., 2020). These initiatives results in massive hit for the travel and tourism sector. For instance, according to the UNWTO's (2021b) assessment, due to the outbreak of COVID-19 pandemic international tourist arrivals declined by about 1 billion or $73 \%$ in 2020 . Along with this in the first quarter of 2021 international tourist arrivals declined by $84 \%$ which is depicting in Figure 1 (UNWTO, 2021b). Moreover, a recent report published by UNCTAD (2021) has revealed that international tourism may loss an amount of more than \$4 trillion to the global GDP for the years 2020 and 2021.

Travel and tourism is one of the most affected sectors by the outbreak of COVID-19 pandemic (Fotiadis et al., 2021; Qiu et al., 2020; Zhang et al., 2021). However, the impacts are more pronounced to those regions and countries where tourism plays the significant role in economic growth (The Commonwealth, 2021). With this respect the Asia-Pacific region has been hardest hit as the region has seen a $65 \%$ to $70 \%$ decrease in tourist arrival (UNWTO, 2021a; WTTC, 2021). In terms of countries, a number of countries have seen the vulnerability in tourism industry during the pandemic. Among them China, Turkey, United States of America, Spain, India, Italy, France, Brazil, and South Korea are most pertinent (Kaushal and Srivastava, 2021; Shakibaei et al., 2021). A large number of people directly or indirectly associated with this sector are at a risk. The recent report by WTTC (2021) can be used to illustrate the impact of this pandemic on tourism service providers and others affiliated with the sector. The report indicates that in 2019 travel and tourism sector has created 1 in 4 of all new jobs across the world which is about 334 million jobs but in 2020 around 62 million people have lost their job in this sector which induced an $18.5 \%$ decrease in number of jobs (WTTC, 2021). In an effort to employ

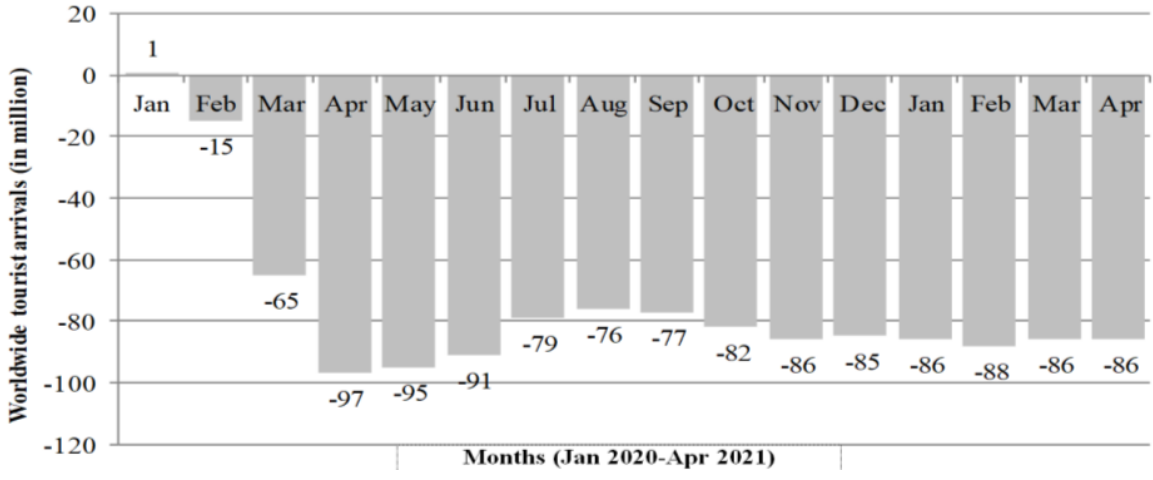

Figure 1. Decreased international tourists arrivals

(in millions/Jan 2020-Apr 2021) (Source: UNWTO,2021b) preventive measures (e.g. washing hands repeatedly, wearing mask, maintaining social distancing) the way of running daily activities have changed (Shamshiripour et al., 2020). Such changes are considered to be features of 'new normal' situation (Kim et al., 2021). Besides, substantial changes are also reflecting in tourists' behavior pattern especially in destination preferences, willingness to travel, and mode of transportation used (European Commission, 2020; Shakibaei et al., 2021; Zafri et al., 2021). For example, tourists now prefer destinations with low tourist density and consider safety and security (hygiene) as a vital attribute of any destination (Chebli and Ben Said, 2020). However, due to the differences in purpose of travel, variations in the impacts of COVID-19 pandemic on different types of tourists has also been reflected. For instance, according to the 'Global Economic Impact' report by WTTC (2021), leisure spending was about US \$4692.4 billion in 2019 which decreased to US \$2373.7 billion in 2020 and business spending has decreased from US $\$ 1294.2$ billion to US $\$ 504.3$ billion.

The impact of COVID-19 on tourism industry is severe in developed countries but worsened in developing countries. Bangladesh is such a country where the tourism industry was growing rapidly but the awful effects of COVID-19 has shattered the tourism industry of Bangladesh (Bhuiyan et al., 2021; Chowdhury, 2020). In 2019 travel and tourism sector of Bangladesh has contributed about BDT 804.5 billion to its national economy but this amount decreased to BDT 539.6 billion in 2020 which represent a fall of 32.9\% (WTTC, 2021). The first case of COVID-19 in Bangladesh was detected on March 8, 2020 (Rahman et al., 2021). Hence, the Government of Bangladesh has declared a nationwide lockdown from March 26 to prevent the spread of the virus. As a result, tourism sector including the other economic sectors of the country has started to collapse (Holy, 2020). According to WTTC (2021) tourism industry of Bangladesh has lost an amount of US $\$ 3.1$ billion in 2020 due to COVID-19 pandemic. Moreover in Bangladesh around 4 million people are directly or indirectly associated with this sector are facing tremendous challenges. For instance, in 2020, around 0.41 million jobs were lost in this sector and 1.45 million remained employed in this sector across the country (WTTC, 2021).Many people travel at some point of their lives. Some people travel for urgent reasons such as for getting treatment, or business and some travel for enjoying leisure and recreation, or visiting friends and relatives (VFR). Everyone has their own reason for travel (Cohen et al., 2014). Based on the needs, the purpose of travel varies. The impact of any crisis on different types of traveler varies too depending on the purpose of travel. For instance during any crisis situation people tends to avoid travelling for leisure activities on the other hand, people with emergency medical needs or treatment mostly don't consider the risk associated with the travel (Sharma et al., 2020). In addition advances in 'Information and Communication Technology' (ICT) have greatly reduced the number of business trips (Shamshiripour et al., 2020). As a result in any crisis situation the tendency of work from home increases among business traveler and they don't prefer to travel without any urgent needs to 
avoid the risk. In this regard, risk perception of travelers can be considered as one of the most influential constituents in causing substantial impact on travel and tourism sector of any crisis (Kovačić et al., 2020; Parady et al., 2020).

A range of internal and external forces influence consumer travel behavior. Among the internal forces an individual's personal attributes such as attitudes, perceptions, values, and beliefs are significant (Chebli and Ben Said, 2020; Heitmann, 2011). On the other hand, among external forces economic and social-cultural environment are considerably significant (Matiza, 2020). In this case travelers with the purpose of visiting friends and relatives are noticeable. In developed countries people with such purpose tends to be very conscious about health related risks but in developing countries such concerns are relatively low (Al-Zaman, 2020). For instance, in Bangladesh many people think that affection is greater than risk, so during any festival they rush to share the joy with their loved ones without caring about anything. Moreover, when the nationwide lockdown was relaxed after the first and second phase of COVID-19 pandemic, the demand for traveling among the people in the country had increased. The reason behind this is that prolonged lockdown cause monotony so when the lockdown is relaxed or lifted, most of the people do not worry much about health related risks but choose travel as the best way to get rid of the monotony (Aziz, 2021). Every tourist is different in terms of their values, attitudes, and perceptions which attracts them distinctively to travel, encourages selecting varied tourism products and services, and creates different level of satisfaction (Cohen et al., 2014). Juvan et al. (2017) have regarded tourists behavior as a key indicator of future trends in travel behavior. Several factors determine consumer travel behavior patterns including purpose of travel, perception of tourists, and motivators of the travel (Vuuren and Slabbert, 2011). Furthermore, travel behavior occurs from stimuli and evaluated according to tourists personal attributes (e.g. values, preferences, attitudes,) but many external factors also often affect tourist's preferences. For example, during any crisis situation, despite having the desire to travel, many people refrain from traveling by thinking about risks associated with it (Kock et al., 2020). Considering the fact that health related risks are much pronounced in influencing tourists' travel decision, the impact of COVID-19 on travel behavior needs to be assessed with a view to determine the new trends in travel behavior (Parady et al., 2020).

In recent years, a growing interest of researchers towards evaluating the relationships between pandemics and travel is quite noticeable. As a result, researchers have been studying the impact of COVID-19 pandemic on travel and tourism since its inception. Many researchers including Foo et al.(2020); Jaipuria et al., (2021); Kock et al., (2020); and Karabulut et al., (2020) have provided significant insight into major disruptions caused by the pandemic and others such as Gössling et al., (2021); Hall et al., (2020) have explored how it is going to change economy of tourism industry. Moreover a number of studies (Kim et al., 2021; Le and Phi, 2021; Qiu et al., 2020; Yeh, 2021; Zhang et al., 2021) have also tried to provide necessary guidance and strategies to minimize the impacts but only a few researchers such as Chebli and Ben Said (2020) and Kock et al. (2020) have concentrated on travel behavior. Thus this study aims at addressing the behaviors of travelers of Bangladesh in relation to COVID-19. Though the pandemic has affected travel behavior pattern of different tourists, this research has assessed the travel patterns in terms of different purposes of visit.

\section{RESEARCH METHODOLOGY}

\section{Data and variables}

In order to serve the purpose of this study a quantitative research method has been utilized. Quantitative research approach can provide clear insights into significant facts and figures for developing an understanding on travel behavior patterns. Researchers such as Mia and Hassan (2021), and Zmud and Sener (2017) often use online survey technique in travel behavior studies to collect necessary data from respondents. As the research took place during the pandemic so it was essential to adopt a survey technique which would be accessible for reaching the respondents easily in a short period of time. Therefore, online survey was regarded as the suitable survey technique for the study. 'Google form' was used to develop the questionnaire and collect responses from the people. After creating the form, it was disseminated among the people for collecting necessary data from them. Various web-based medium such as email and social networking sites were used to collect responses from the respondents in a short period of time. The survey was carried out during the lockdown period in Bangladesh. The survey questionnaire included two parts. The first part of the survey was designed to collect socio-demographic information of the respondents. Another part of the questionnaire was designed to collect information about pre and during COVID-19 travel characteristics of the respondents. The respondents were asked to provide details about their trips before the pandemic (COVID-19 outbreak) and during the pandemic for last one year. The details included respondents' purpose of travel, frequency of taking domestic trips and outbound travel.The study has utilized nonprobability convenience sampling method. A total of 300 responses were collected from the people. The sample covers respondents from different geographic locations and socio-demographic characteristics. The questions contained in survey instrument were pre-tested by the authors of the current research prior to collecting data from the respondents. The collected data were coded and analyzed by using the Statistical Package for Social Science (SPSS) version 23.0 and RStudio. With a view to addressing the aim of this research, a number of statistical techniques such as box plots, error diagrams and generalized linear modeling (GLM) specifically Poisson regression have been applied.

\section{Model fitting}

In this study, numbers of domestic and international visits are considered as dependent variables. Since the dependent variables are count data instead of linear regression, Poission regression, negative binomial regression and Poission regression using quasi-likelihood approach have been considered here. Poisson regression modelling have been widely used in a number of COVID-19 data such as forecasting number of deaths, transmission of disease and playing soccer during COVID-19 (Benz and Lopez, 2021; Kim et al., 2020; Odhiambo et al., 2020). 
Poisson regression: For count data, the Poisson distribution named after Simeon Denis Poisson can be used to obtain the probability of events within fixed time interval (Haight, 1967). The Poisson variable $Y_{i}$ has the following probability mass function $f\left(y_{i}\right)=\frac{\mu_{i} y_{i} e^{-\mu_{i}}}{y_{i}}, y_{i}=0,1,2,3, \ldots \ldots$ Where, $e$ has a constant value of 2.71828 . This distribution has the property that both the mean and variance are equal to $\mu_{i}$. Let $x_{i j}$ be the value of the $j^{\text {th }}$ explanatory variable corresponding to the $i^{\text {th }}$ observation. The Poisson regression model by McCullagh and Nelder (2019) can be represented as $\log \left(\mu_{i}\right)=\eta_{i}=\sum_{i j} x_{i j} \beta_{j}$ where, $\beta_{j}(j=1,2, \ldots, p)$ are the model parameters and $\eta_{i}$ is the linear predictor. The modelparameters $\beta_{1}, \ldots, \beta_{p}$ can be estimated using maximum likelihood method.

Overdispersion in Poisson regression: For Poisson response variables, a common form of problem that leads to the distribution assumed for the response variable being inappropriate is known as overdispersion (note that sometimes the problem may be underdispersion, although this is less often). This means that the variance of the response variable is larger than we would have expected. It is good practice to assume that overdispersion will be present unless there is good reason to believe otherwise. If any overdispersion is ignored when it is present, the confidence intervals of the regression parameters will tend to be too narrow, in that there is more unexplained variation and therefore more uncertainty, than we have allowed for. We can use the quasi-likelihood method, which allows for overdispersion by estimating the dispersion parameter and using this to adjust the results from the analysis involving the Poisson model. This type of analysis only requires specification of the mean and the variance, not of the likelihood itself. We only specify, $E\left(Y_{i}\right)=\mu_{i}$ and $V\left(Y_{i}\right)=\varphi v\left(\hat{\mu}_{i}\right)$, where $v\left(\mu_{i}\right)$ is the variance function. An alternative approach is to start with a model that might better fit the data. A natural way to do this is to include some extra variation in the model, in a manner that we hope matches what is happening in the data-generation process. In general, we might therefore consider a model in which $\mu_{i}$ is allowed to vary amongst observations with the same values for the predictor variables, $y_{i}$ will then have what is often referred to as a mixture distribution. We assume that, $\mu_{i} \sim \Gamma\left(\alpha_{i}, k\right)$ thus $\mu_{i}$ has a gamma distribution, with probability function

$$
\begin{gathered}
f\left(\mu_{i}\right)=\frac{1}{\Gamma(k)}\left(\frac{k}{\alpha_{i}}\right)^{k} \mu_{i}^{k-1} \exp \left(-\frac{k \mu_{i}}{\alpha_{i}}\right), k>0, \alpha_{i}>0, \mu_{i} \geq 0 \text { Then } y_{i} \text { has a negative binomial distribution, with } \\
\text { probability function }
\end{gathered}
$$

Akaike's information criterion: An approach of model selection from many possible models is to use Akaike's information criterion. It is defined asAIC $=-2 l+2 p$,where $l$ is maximized log-likelihood for the model and $p$ is the number of parameters of the model. AIC provides a theoretically-underpinned compromise between having a model that fits the data well and one that is as simple as possible, i.e. has few parameters. AIC determines the relative quality of statistical models for a given set of data. A small sample version of AIC is given by

$$
\begin{array}{ll}
\text { AICc }=-2 l+\frac{2 p n}{n-p-1} . & \begin{array}{l}
\text { Among a set of candidate models a preferred model is that with the lowest AIC. A modification } \\
\text { to the formula for AIC that allows for overdispersion is the quasi-AIC, which is defined as }
\end{array} \\
\text { In this study, all the three candidate models Poisson, quasi-Poisson and negative binomial } \\
\text { models are fitted to data set by considering domestic and international visits as the dependent }
\end{array}
$$

purpose. On the other hand, for international visits model domestic visits, year of visits and purpose are the considered explanatory variables. Akaike's information criterion is used to select one model from the three candidate models for each dependent variable.

\section{Findings of the study}

At the very outset, the boxplot and error bar diagram for the domestic and international visits are plotted against the variables year and purpose, in order to understand the pattern of relationship between them.In Figure 2 the number of domestic visits and international visits before and during the COVID-19 pandemic is presented. The median number of domestic visits is approximately 2 and about 75\% respondents made between 2 to 3 domestic visits before COVID in the year 2019. On the other hand, the median number of domestic visits is approximately 1 and about $75 \%$ of the respondents made between 0 to about 2 domestic visits during COVID (year 2020). Some outliers are seen in both the situations. In case of the international visits, the median value for the respondents is 0 before COVID.

However, about $75 \%$ of the respondents made between 0 to 1 international visits before COVID. On the contrary, during COVID at least $75 \%$ of the respondents made no international visits. Note that, in Figure 2, the data has outliers especially at the upper side, therefore, to understand the pattern easily scaling of the boxplots are changed that is the yaxis values are fixed at $0-6$ in case of domestic visits and 0-2 in case of international visits.

In Figure 3 the error bar chart for mean number of domestic and international visits of the respondents before and during COVID are displayed for different levels of the purpose variable. The circles at the middle indicate the mean number of visits and the lines indicate the $95 \%$ confidence intervals of the mean. It is clear (from the Figure 3, a) that, for different purposes the mean number of domestic visits of the respondents clearly decreases during the COVID outbreak (year 2020). Also, the mean number of international visits decreases during COVID except the leisure purpose which remains approximately the same (Figure 3, b ). The average numbers of domestic and international visits are the highest for business purpose, although the variability is also the highest for this purpose in both the years. VFR is the 
second highest purpose and the last three purposes are leisure, medical and others respectively for domestic visits. On the other hand, unlike the domestic visits the second highest reason for the international visits is the medical checkup.
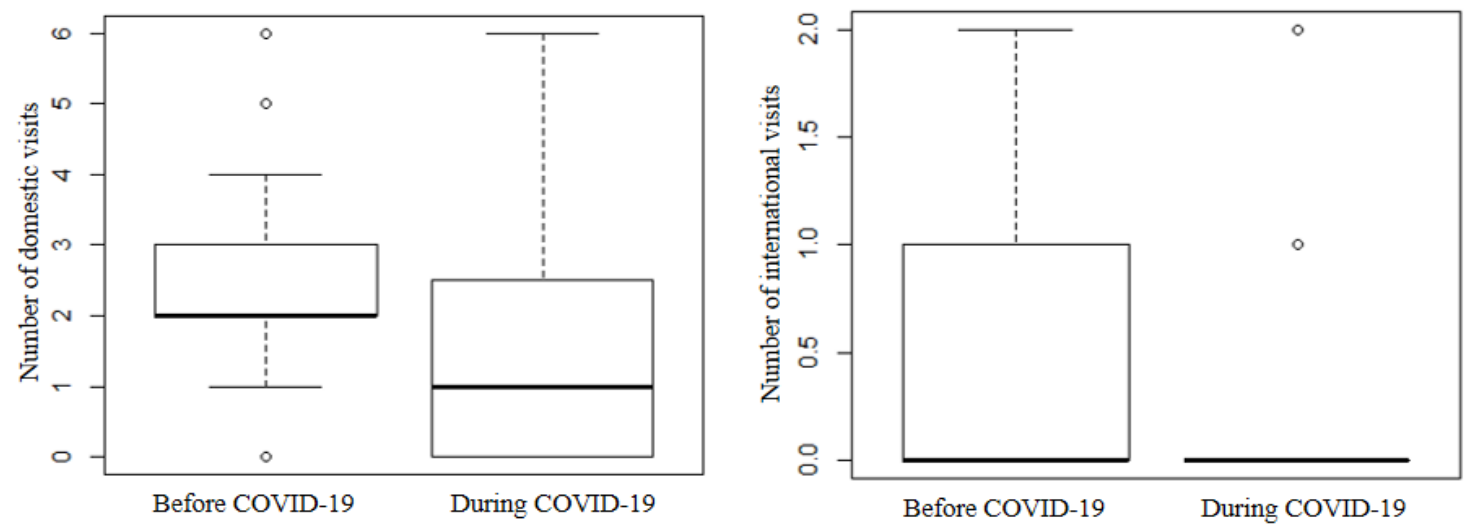

Figure 2. Number of visits before and during COVID-19 pandemic
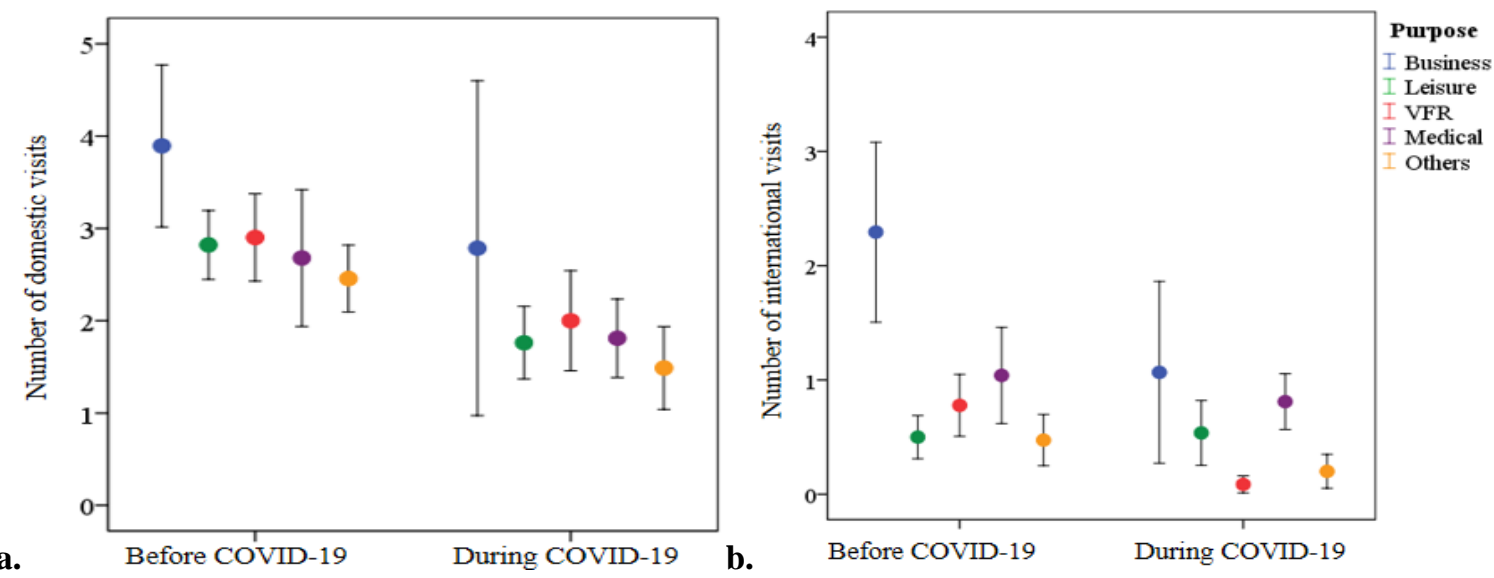

Figure 3. 95\% CI of the mean number of visits for different purpose

From Table 1 and Table 2 it is observed that, the coefficients for Poisson and quasi-Poisson models are exactly same, however the standard errors and the corresponding p-values are different. Coefficients for Negative-binomial models are close to those of Poisson and quasi-Poisson models and again the standard errors and the corresponding p-values are different. As for example, for the domestic visits (Table 1) the category visiting friends of the purpose variable is significant in Poisson model ( $p$-value $<0.05$ ), on the other hand this category is insignificant in quasi-Poisson model (pvalue $>0.10$ ) and Negative-binomial model (p-value $>0.10$ ). Likewise, for the international travel (Table 2) the category medical purpose is significant in Poisson model (p-value<0.10), on contrary this category is insignificant in Negativebinomial model ( $\mathrm{p}$-value $>0.10$ ) and in quasi-Poisson model ( $\mathrm{p}$-value $>0.10$ ). AIC for the 3 models for both domestic and international visits are calculated. It is apparent that, quasi-likelihood models are preferable compared to other two models in both cases, as the AIC values are the lowest for this model.

Table 1. Estimates of Poisson, Negative-binomial and Quasi-Poisson regression model for domestic visits

\begin{tabular}{|c|c|c|c|c|c|}
\hline \multicolumn{6}{|l|}{ Poisson (AIC=1899.615) } \\
\hline Variable & $\bar{\beta}$ & S.E. & Z/t-value & p-value & $\operatorname{Exp}(\bar{\beta})$ \\
\hline Year $(\operatorname{Ref}=2019) 2020$ & -0.420 & 0.063 & -6.698 & $2.59 \times 10^{-11}$ & 0.657 \\
\hline Purpose (Ref=Business) - Leisure & $-0.326^{* \ldots m}$ & 0.117 & -2.799 & 0.00513 & 0.722 \\
\hline Visiting friend & $-0.238^{*}$ & 0.115 & -2.071 & 0.03832 & 0.788 \\
\hline Medical & $-0.350^{* * * *}$ & 0.128 & -2.724 & 0.00645 & 0.705 \\
\hline Other & $-0.467^{* * *}$ & 0.119 & -3.928 & $8.5 \times 10^{-05}$ & 0.627 \\
\hline \multicolumn{6}{|l|}{ Negative-binomial (AIC=1866.935) } \\
\hline Year $(\operatorname{Ref}=2019) 2020$ & $-0.421^{\circ}$ & 0.073 & -5.721 & $1.06 \times 10^{-08}$ & 0.656 \\
\hline Purpose (Ref=Business) - Leisure & $-0.328^{* 21}$ & 0.144 & -2.286 & 0.0227 & 0.720 \\
\hline Visiting friend & -0.237 & 0.142 & -1.668 & 0.9532 & 0.789 \\
\hline Medical & $-0.348^{* *}$ & 0.156 & -2.238 & 0.02523 & 0.706 \\
\hline Other & $-0.469^{* * *}$ & 0.145 & -3.231 & 0.00123 & 0.626 \\
\hline \multicolumn{6}{|l|}{ Quasi-Poisson $(\mathrm{AIC}=1272.053)$} \\
\hline Year $($ Ref $=2019) 2020$ & $-0.420^{n+1}$ & 0.080 & -5.227 & $2.56 \times 10^{-07}$ & 0.657 \\
\hline Purpose (Ref=Business) - Leisure & -0.326 & 0.149 & -2.194 & 0.02872 & 0.722 \\
\hline Visiting friend & -0.238 & 0.147 & -1.624 & 0.10507 & 0.788 \\
\hline Medical & $-0.349^{* *}$ & 0.164 & -2.135 & 0.03324 & 0.705 \\
\hline Other & $-0.467^{* *}$ & 0.152 & -3.079 & 0.00219 & 0.627 \\
\hline
\end{tabular}

$* \mathrm{p}<0.1, * * \mathrm{p}<0.05, * * * \mathrm{p}<0.01$ 
From Table 1 using the results for quasi-Likelihood models it is apparent that, in the year 2020 domestic travelers are expected to travel outside their district $34.3 \%$ less than the year 2019, assuming the remaining covariates held constant. Domestic travelers are expected to travel less for leisure, VFR, medical or other purposes compared to the business purpose. More specifically, for medical purpose the average number of travels is $29.5 \%$ less compared to the business purpose.From Table 2 using the results for quasi-Likelihood models it is found that, domestic travel is an important determinant of international travel. More specifically, with 10 units increase in domestic travel the average number of international travels increased by 1.12 units. The average number of international travels decreased by $44.6 \%$ in the year 2020 compared to the year 2019. Similar to the results of domestic travel, average number of travels for leisure, visiting friends, or other purposes are less compared to the business purpose in case of international travel.

Table 2. Estimates of Poisson, Negative-binomial and Quasi-Poisson regression model for international visits

\begin{tabular}{|c|c|c|c|c|c|}
\hline Variable & $\widehat{\boldsymbol{\beta}}$ & S.E. & $\mathrm{Z}$ value & p-value & $\operatorname{Exp}(\widehat{\boldsymbol{\beta}})$ \\
\hline \multicolumn{6}{|l|}{ Poisson (AIC=1021.441) } \\
\hline Domestic Visit & $0.112^{* \pi}$ & 0.022 & 4.806 & $5.88 \times 10^{-06}$ & 1.118 \\
\hline Year $(\operatorname{Ref}=2019) 2020$ & $-0.589^{\circ}$ & 0.116 & -4.182 & $5.04 \times 10^{-06}$ & 0.554 \\
\hline Purpose (Ref=Business)Leisure & $-1.104^{* \cdots *}$ & 0.178 & -7.455 & $9.32 \times 10^{-09}$ & 0.331 \\
\hline Visiting friend & $-1.091^{* * * *}$ & 0.169 & -7.502 & $6.92 \times 10^{-09}$ & 0.336 \\
\hline Medical & $-0.316^{*}$ & 0.168 & -2.915 & 0.0968 & 0.729 \\
\hline Other & $-1.375^{* * *}$ & 0.190 & -8.069 & $7.52 \times 10^{-11}$ & 0.253 \\
\hline \multicolumn{6}{|c|}{ Negative-binomial (AIC=986.5831) } \\
\hline Domestic Visit & $0.157^{* \pi m}$ & 0.034 & 4.606 & $4.10 \times 10^{-06}$ & 1.170 \\
\hline Year $(\operatorname{Ref}=2019) 2020$ & -0.564 & 0.165 & -3.410 & 0.000648 & 0.569 \\
\hline Purpose (Ref=Business)Leisure & -0.990 & 0.281 & -3.518 & 0.000434 & 0.372 \\
\hline Visiting friend & $-1.059^{* * *}$ & 0.279 & -3.784 & 0.000155 & 0.347 \\
\hline Medical & -0.202 & 0.288 & -0.288 & 0.484001 & 0.817 \\
\hline Other & $-1.297^{* * *}$ & 0.294 & 0.294 & $1.05 \times 10^{-05}$ & 0.273 \\
\hline \multicolumn{6}{|l|}{ Quasi-likelihood (AIC=680.2056) } \\
\hline Domestic Visit & $0.112^{* \ldots+m}$ & 0.029 & 3.682 & 0.000256 & 1.118 \\
\hline Year $(\operatorname{Ref}=2019) 2020$ & -0.589 & 0.152 & -3.204 & 0.000231 & 0.554 \\
\hline Purpose (Ref=Business)Leisure & -1.104 & 0.232 & -5.712 & $3.92 \times 10^{-06}$ & 0.331 \\
\hline Visiting friend & $-1.091^{* * *}$ & 0.221 & -5.748 & $3.23 \times 10^{-06}$ & 0.336 \\
\hline Medical & -0.316 & 0.220 & -2.233 & 0.177592 & 0.729 \\
\hline Other & $-1.375^{* * *}$ & 0.248 & -6.182 & $1.82 \times 10^{-07}$ & 0.253 \\
\hline
\end{tabular}

\section{DISCUSSION}

This study has assessed the impacts of COVID-19 on travel behavior in Bangladesh. According to many researchers, any crisis can severely affect travel behavior of tourists and undoubtedly health related crisis has been among one of the most influential crises affecting travel and tourism activities (Chebli and Ben Said, 2020; Matiza, 2020; Shamshiripour et al., 2020; Uğur and Akbıyık, 2020; Gössling et al., 2021). The same thing is reflecting too in this study (Figure 2) and by carefully noticing the figures one can clearly understand how the ongoing global pandemic COVID-19 is affecting travel behavior of tourists. According to the figures (Figure 2) presented in this study, both the numbers of domestic travel and international travel have decreased. One of the reasons for the similarity of the findings of this study with the findings of other studies is that tourists generally assess the risks associated with any trip before taking a travel decision. If the perceived risk is larger than the significance of travel, tourists mostly avoid travelling. The number of visits for various purposes decreased substantially both in domestic and international travel which is shown in Figure 3 and these findings agree with other studies by European Commission (2020), WTTC (2021), UNWTO (2021b), UNCTAD (2021), and The Commonwealth (2021). The scenarios presented in those figures are quite similar for both domestic tourism and international tourism except for leisure travel. There is no change in the level of international visits for leisure purposes before and during the pandemic which conflicts with findings of other studies by Kumar (2020) (Figure 3). It could be because of the risk perception of travelers which is mainly depends on the values, attitudes, beliefs and other personal factors of travelers as suggested by Cohen et al. (2014). Many travelers think that health related safety and hygiene concerns in other countries are better than Bangladesh thus they prefer to take outbound trip rather domestic. In the context of both domestic travel and international travel the mean number of visits for business purposes was highest before and during COVID-19 pandemic depicting in Figure 3. This fact about the findings contradicts with the findings of the study by WTTC (2021) where it is described that the impact of the pandemic is more severe to business spending than leisure spending. One of the reason behind this incompatibles could be low awareness among the people of Bangladesh about health related risks which is suggested by Al-Zaman (2020). Another fact is that many developed nations with their advanced ICT could easily adapt to the changes took place due to the pandemic, such as work from home, conducting virtual meetings and teleconferencing. Though such tendencies are taking place in Bangladesh too but with relatively lower than the other countries.

In case of domestic visit, Figure 3 demonstrates that the mean number of trips with purpose of VFR is the highest after business trips and in international travel visits for medical purposes are the highest after business trips. Reason underlying the fact that, people with medical purposes travels when they find healthcare facilities available in their areas are not well enough for them so they choose visiting oversees with a view to getting proper treatment as suggested by Sharma et al.,(2020). Therefore, it can be affirmed that poor healthcare system existing in Bangladesh compels many people to travel which is coherent with the study by Al-Zaman (2020). Findings of this study reflect (Table 1), in terms of domestic 
tourism, travel associated with business purposes are expected to be more than with other purposes (e.g. leisure, medical, VFR, and other purposes) presented in this study. Additionally, this study finds domestic travel can be used as a significant determinant for projecting international travel which is demonstrated in Table 2. Such information can be very helpful to tourism stakeholders including destination management organizations and tourism service providers who can easily forecast tourism demand and ensure the availability of certain tourism products and services. Besides projected travel demand can play a considerable role in formulating and implementing crisis response strategies. As a result, these strategies can help the tourism industry of Bangladesh to recover soon from the losses by COVID-19.

\section{CONCLUSION}

The global tourism industry is experiencing an unprecedented circumstance due to the ongoing pandemic COVID-19. The effects of the pandemic had not been limited to a specific area or region like other epidemics. Rather, it has spread across different regions and countries of the world including Bangladesh. As a result, the economies and its related sectors of Bangladesh have been severely affected. This magnitude of the pandemic has raised the need for exploring impacts on travel and tourism sector. As noted earlier, a number of studies have conducted relating to assessing the impact of the pandemic on travel and tourism as a whole. Nevertheless, the impacts on travel behavior of different types of tourists have not been yet assessed which is a prerequisite for formulating policy and strategy. This study has attempted to incorporate such research gap by providing significant insights into the scenarios of both domestic travel and international travel along with the perspective from different traveler with varied purpose. This study has assessed impacts of COVID-19 pandemic on travel behavior of people in terms of purpose of visit. In order to accomplish the research aim, this study has utilized quantitative research approach by performing descriptive studies and generalized linear modeling (GLM). The findings indicate that the mean number of both domestic travel and international travel decreased significantly, 34.3\% and $44.6 \%$ respectively due to the outbreak of COVID-19 pandemic. As tourists are very sensitive to crisis so such impacts are apparent. This study also finds domestic travel as a determinate to international travel which can be used to project future travel demand of international tourism. However, findings with respect to impact on travelers with different purpose of visit (i.e. business, leisure, medical, VFR and other purposes), demonstrates that patterns of travels have significantly changed during the pandemic, except travel for leisure in abroad. The study also projects domestic and international travelers will travel less for leisure, visiting friends, medical or other purposes compared to the business purpose during COVID-19.

Bangladesh is a developing country and tourism play a significant role in economic development of the country. Bangladesh has faced a hardest hit by COVID-19 like the global tourism industry thus to recover from this effects fruitful strategies and effective policy is essential where such studies can act as valuable tool. This research has been done on a very small scale with a little sample size. Hence, if such research is done on a larger scale it will provide with more reliable results. Future researchers may look into the new trends or patterns of travel behavior taking place among travelers due to the pandemic, major concerns of travelers while traveling during pandemic situation, travel demand projections in relation to the rate of vaccination in the country. Another line of enquiry would be to assess how the vaccination rate against the population can help tourism industry in recovering from the negative impacts of the pandemic. It is quite difficult for a developing country like Bangladesh to recover from the losses caused by COVID-19 pandemic but patronages from the Government and concerted efforts of concerned stakeholders can help in recovering from the effects soon. Therefore, integrated efforts from both public sector and private sector are required to rejuvenate the tourism industry in Bangladesh.

\section{REFERENCES}

Al-Zaman, Md.S. (2020). Healthcare Crisis in Bangladesh during the COVID-19 Pandemic. The American Society of Tropical Medicine and Hygiene, 103(4), 1357-1359. https://doi.org/10.4269/ajtmh.20-0826

Aziz, A. (2021). Cox's Bazar back to life as tourists crowd beaches. Dhaka Tribune. https://www.dhakatribune.com/bangladesh/ nation/2021/08/19/cox-s-bazar-back-to-life-as-tourist-crowd-beaches

Bakar, N.A., \& Rosbi, S. (2020). Effect of Coronavirus disease (COVID-19) to tourism industry. International Journal of Advanced Engineering Research and Science, 7(4), 189-193. https://doi.org/10.22161/ijaers.74.23

Benz, L.S., \& Lopez, M.J. (2021). Estimating the change in soccer's home advantage during the Covid-19 pandemic using bivariate Poisson regression. AStA Advances in Statistical Analysis, 1-28. https://arxiv.org/pdf/2012.14949v2.pdf

Bhuiyan, M.B., Islam, Md.A., Haque, Md. Z., \& Hassan, Md. K. (2021). Dynamics and Causality Among Economic Growth, Financial Development and Budgetary Allocation To The Tourism Sector Of Bangladesh. GeoJournal of Tourism and Geosites, 35(02), 419427. https://doi.org/10.30892/gtg.35221-668

Chebli, A., \& Ben Said, F. (2020). The Impact of Covid-19 on Tourist Consumption Behaviour: A Perspective Article. Journal of Tourism Management Research, 7(2), 196-207. https://doi.org/10.18488/journal.31.2020.72.196.207

Chowdhury, D.E.K. (2020). Catastrophic Impact of Covid-19 on Tourism Sector in Bangladesh: An Event Study Approach. The Cost Management, 48(04), 43-52. http://www.icmab.org.bd/wp-content/uploads/2020/09/4.Catastrophic.pdf

Cohen, S.A., Prayag, G., \& Moital, M. (2014). Consumer behaviour in tourism: Concepts, influences and opportunities. Current Issues in Tourism, 17(10), 872-909. https://doi.org/10.1080/13683500.2013.850064

Foo, L.P., Chin, M.Y., Tan, K.L., \& Phuah, K.T. (2020). The impact of COVID-19 on tourism industry in Malaysia. Current Issues in Tourism, 1-5. https://doi.org/10.1080/13683500.2020.1777951

Fotiadis, A., Polyzos, S., \& Huan, T.C.T.C. (2021). The good, the bad and the ugly on COVID-19 tourism recovery. Annals of Tourism Research, 87, 103117. https://doi.org/10.1016/j.annals.2020.103117

Gössling, S., Scott, D., \& Hall, C.M. (2021). Pandemics, tourism and global change: A rapid assessment of COVID-19. Journal of Sustainable Tourism, 29(1), 1-20. https://doi.org/10.1080/09669582.2020.1758708

Hall, C.M., Scott, D., \& Gössling, S. (2020). Pandemics, transformations and tourism: Be careful what you wish for. Tourism Geographies, 22(3), 577-598. https://doi.org/10.1080/14616688.2020.1759131

Haight, Frank, A. (1967). Handbook of the Poisson Distribution, New York, NY, USA: John Wiley \& Sons, ISBN 978-0-471-33932-8. https://catalogue.nla.gov.au/Record/529287 
Hassan, K., \& Ferdaus, J. (2020). Crisis Management in the Hospitality Industry: Issues and Future Strategies. In S. R. Hasan, S. Nagpal, \& D.P. Sahu (Eds.), Recent Trends in Hospitality Operation (pp. 38-61). Wisdom Publication.

Heitmann, S. (2011). Tourist Behaviour and Tourism Motivation. In P. Robinson, S. Heitmann, \& P.U.C. Dieke (Eds.), Research themes for tourism, 31-44, CABI

Holy, I.J. (2020). COVID-19 \& Tourism: A Tragic End to the Thriving Industry? Light Castle Partners. https://www.lightcastlebd.com/ insights/2020/06/covid-19-tourism-a-tragic-end-to-the-thriving-industry

Hussain, A., \& Fusté-Forné, F. (2021). Post-Pandemic Recovery: A Case of Domestic Tourism in Akaroa (South Island, New Zealand). World, 2(1), 127-138. https://doi.org/10.3390/world2010009

Jaipuria, S., Parida, R., \& Ray, P. (2021). The impact of COVID-19 on tourism sector in India. Tourism Recreation Research, 46(2), 245-260. https://doi.org/10.1080/02508281.2020.1846971

Juvan, E., Omerzel, D.G., \& Maravić, M.U. (2017). Tourist Behaviour: An Overview of Models to Date. Management International Conference.

Karabulut, G., Bilgin, M.H., Demir, E., \& Doker, A.C. (2020). How pandemics affect tourism: International evidence. Annals of Tourism Research, 84. https://doi.org/10.1016/j.annals.2020.102991

Kaushal, V., \& Srivastava, S. (2021). Hospitality and tourism industry amid COVID-19 pandemic: Perspectives on challenges and learnings from India. International Journal of Hospitality Management, 92, 102707. https://doi.org/10.1016/j.ijhm.2020.102707

Kim, J., Kim, J., \& Wang, Y. (2021). Uncertainty risks and strategic reaction of restaurant firms amid COVID-19: Evidence from China. International Journal of Hospitality Management, 92, 102752. https://doi.org/10.1016/j.ijhm.2020.102752

Kim, T., Lieberman, B., Luta, G., \& Pena, E. (2020). Prediction Regions for Poisson and Over-Dispersed Poisson Regression Models with Applications to Forecasting Number of Deaths during the COVID-19 Pandemic. arXiv preprint arXiv:2007.02105. https://arxiv.org/abs/2007.02105

Kock, F., Nørfelt, A., Josiassen, A., Assaf, A.G., \& Tsionas, M.G. (2020). Understanding the COVID-19 tourist psyche: The Evolutionary Tourism Paradigm. Annals of Tourism Research, 85, 103053. https://doi.org/10.1016/j.annals.2020.103053

Kovačić, S., Mărgărint, M.C., Ionce, R., \& Miljković, Đ. (2020). What are the Factors affecting Tourist Behavior based on the Perception of Risk? Romanian and Serbian Tourists' Perspective in the Aftermath of the recent Floods and Wildfires in Greece. Sustainability, 12(16), 6310. https://doi.org/10.3390/su12166310

Kumar, D.A. (2020). Disastrous impact of Coronavirus (COVID 19) on Tourism and Hospitality Industry in India. Journal of Xi'an University of Architecture \& Technology, 12(05), 698-712. http://xajzkjdx.cn/gallery/69-may2020.pdf

Le, D., \& Phi, G. (2021). Strategic responses of the hotel sector to COVID-19: Toward a refined pandemic crisis management framework. International Journal of Hospitality Management, 94, 102808. https://doi.org/10.1016/j.ijhm.2020.102808

Matiza, T. (2020). Post-COVID-19 crisis travel behaviour: Towards mitigating the effects of perceived risk. Journal of Tourism Futures, ahead-of-print(ahead-of-print). https://doi.org/10.1108/JTF-04-2020-0063

McCullagh, P., \& Nelder, J.A. (2019). Generalized linear models. Routledge. https://www.routledge.com/Generalized-LinearModels/McCullagh-Nelder/p/book/9780412317606

Mia, M.N., \& Hassan, K. (2021). Post COVID challenges to the tourism and hospitality industry: a study on Bangladesh, Can. J. Bus. Inf. Stud., 3(6), 109-119. https://doi.org/10.34104/cjbis.021.01090119

Odhiambo, J.O., Ngare, P., Weke, P., \& Otieno, R.O. (2020). Modelling of covid-19 transmission in kenya using compound poisson regression model. Journal of Advances in Mathematics and Computer Science, 101-111. https://doi.org/10.9734/jamcs/2020/v35i230252

Parady, G., Taniguchi, A., \& Takami, K. (2020). Travel behavior changes during the COVID-19 pandemic in Japan: Analyzing the effects of risk perception and social influence on going-out self-restriction. Transportation Research Interdisciplinary Perspectives, 7, 100181. https://doi.org/10.1016/j.trip.2020.100181

Qiu, R.T.R., Park, J., Li, S., \& Song, H. (2020). Social costs of tourism during the COVID-19 pandemic. Annals of Tourism Research, 84, 102994. https://doi.org/10.1016/j.annals.2020.102994

Rahman, M., Sajib, E., Chowdhury, I., Banik, A., Bhattacharya, R., \& Ahmed, H. (2021). Present scenario of COVID-19 in Bangladesh and government preparedness for facing challenges. Journal of Advanced Biotechnology and Experimental Therapeutics, 4(2), 187. https://doi.org/10.5455/jabet.2021.d119

Shakibaei, S., de Jong, G.C., Alpkökin, P., \& Rashidi, T.H. (2021). Impact of the COVID-19 pandemic on travel behavior in Istanbul: A panel data analysis. Sustainable Cities and Society, 65, 102619. https://doi.org/10.1016/j.scs.2020.102619

Shamshiripour, A., Rahimi, E., Shabanpour, R., \& Mohammadian, A. (2020). How is COVID-19 reshaping activity-travel behavior? Evidence from a comprehensive survey in Chicago. Transportation Research Interdisciplinary Perspectives, 7, 1-16. https://doi.org/10.1016/j.trip.2020.100216

Sharma, A., Vishraj, B., Ahlawat, J., Mittal, T., \& Mittal, M. (2020). Impact of COVID-19 outbreak over Medical Tourism. IOSR Journal of Dental and Medical Sciences (IOSR-JDMS), 19(05), 56-58. https://doi.org/10.9790/0853-1905145658

Uğur, N.G., \& Akbiylk, A. (2020). Impacts of COVID-19 on global tourism industry: A cross-regional comparison. Tourism Management Perspectives, 36, 1-13. https://doi.org/10.1016/j.tmp.2020.100744

Vuuren, C.V., \& Slabbert, E. (2011). Travel Motivations and Behaviour Of Tourists To A South African Resort. Management Studies, 01, 295-304. http://tmstudies.net/index.php/ectms/article/viewFile/196/253

Yeh, S.S. (2021). Tourism recovery strategy against COVID-19 pandemic. Tourism Recreation Research, 46(2), $188-194$. https://doi.org/10.1080/02508281.2020.1805933

Zafri, N.M., Khan, A., Jamal, S., \& Alam, B.M. (2021). Impacts of the COVID-19 Pandemic on Active Travel Mode Choice in Bangladesh: A Study from the Perspective of Sustainability and New Normal Situation. Sustainability, 13(12), 6975. https://doi.org/10.3390/su13126975

Zhang, H., Song, H., Wen, L., \& Liu, C. (2021). Forecasting tourism recovery amid COVID-19. Annals of Tourism Research, 87, 1-16. https://doi.org/10.1016/j.annals.2021.103149

Zmud, J.P., \& Sener, I.N. (2017). Towards an understanding of the travel behavior impact of autonomous vehicles. Transportation research procedia, 25, 2500-2519. https://doi.org/10.1016/j.trpro.2017.05.281

*** European Commission. (2020). Behavioural changes in tourism in times of Covid-19: Employment scenarios and policy options. (Behavioural Changes in Tourism in Times of Covid-19). Publications Office. https://data.europa.eu/doi/10.2760/00411

*** The Commonwealth. (2021). Tourism and COVID-19: Mapping a Way Forward for Small States, 1-30.

*** UNCTAD. (2021). COVID-19 and Tourism An Update (Assessing the Economic Consequences). www.unctad.org

*** UNWTO. (2021a). Global Economy Could Lose Over 4 Trillion Due To Covid-19 Impact On Tourism. www.unwto.org

*** UNWTO. (2021b). Impact Assessment of the Covid-19 Outbreak on International Tourism. United Nations World Tourism Organization. www.unwto.org

*** WHO. (2021). About Coronavirus disease (COVID-19). www.who.org

*** WTTC. (2021). Global Economic Impact and Trends 2021.pdf. www.wttc.org 